\title{
Oral hygiene practices, its associated factors and evaluation of oral health education package among 6-8 grade students of bajrabarahi municipality, Lalitpur
}

\begin{abstract}
Summary
Oral health is recognized as equally important in relation to general health. Proper oral hygiene is the fundamental basis of the common risk factor approach to prevent the oral diseases. Dental caries is the common oral pathology that remain widely prevalent among all populations throughout the lifespan. The school years cover a period that runs from childhood to adolescence. These are influential and receptive stages in people's lives when lifelong sustainable oral health related behaviors, as well as beliefs and attitudes, are being developed. Children may also be equipped with personal skills that enable them to make healthy decisions. So school may be considered as an ideal setting for conducing successful health programs. This study provides important information to identify the oral hygiene practices and aims to implement the oral health education package among school students. The objective of the study is to identify the status of oral hygiene practices, its associated factors, and evaluate the effectiveness of oral health education package in improving the practices on oral hygiene among the students of 6-8 grade of Bajrabarahi Municipility of Lalitpur District. The school based action research was conducted among the students of grade 6-8 of Bajrabarahi Municipality. The study was completed in three phases. The phase I was Baseline study Phase, this phase was conducted to identify the status and gaps on oral hygiene practices. Phase II was the package development phase, from the findings of the baseline study the intervention package on oral hygiene was developed. Phase III was implementation phase, in this phase the implementation and evaluation of health education package on oral hygiene practices was done. Baseline study was conducted in total 5 secondary private school of Bajrabarahi Municipality which was selected randomly and all the students of class 6-8 were selected as a study population. Quantitative technique was used for the data collection the self-administered questionnaire was employed to collect the information from the students. Cross sectional study design was applied for the baseline study.
\end{abstract}

Data entry and analysis was done on SPSS 21 version Study reveals that 100\% of the respondents brush their teeth daily. Only $37.6 \%$ of the student brush their teeth twice a day. Majority of the student use toothpaste and toothbrush
Volume 5 Issue 2 - 202I

Roshani Poudel, Basanta Chalise
Department of Public Health, Tribhuwan University, Nepal

Correspondence: Basanta Chalise, Department of Public Health, Tribhuwan University, Nepal, Email Chalisebt@gmail.com

Received: January 21, 202I | Published: March 15, 2021

to clean their teeth. $54 \%$ of the respondent change their toothbrush more than 6 month. Among the participants $23.9 \%$ followed the appropriate technique of brushing. $55 \%$ of the participant used to rinse their mouth after major meal and $45 \%$ rinse their mouth only after major meal. Only $20.2 \%$ of the participant used to visit dentist every 6 month. Regarding the status of oral hygiene practice more than fifty percent of the participant have below average practice on oral hygiene $(55.8 \%)$. Regarding knowledge only $36.1 \%$ participants have knowledge on proper techniques of brushing. $85.2 \%$ have above or equal average knowledge on oral hygiene. The education level of the mother and perceived barrier was found significantly associated with oral hygiene practice. The second phase of the study was package development phase. In this phase package on oral hygiene was developed according to the information obtained from the baseline study. From the baseline findings the package was developed on proper technique of brushing. Package was developed by analyzing the methods media and content. The third phase of the study was to implement and evaluate of the oral health education package. Package was implemented in 2 school among those 5 school where the baseline was conducted and remain 3 school were considered as control school. From the analysis of comparison between intervention and control group the oral health education package was found to be effective in changing knowledge, belief and practice among the student in the intervention group.

\section{Introduction}

\section{Background}

Oral health is essential and important part of general health and quality of life. It is a state of being free from mouth and facial pain, oral and throat cancer, oral infection and sores, periodontal (gum) disease, tooth decay, tooth loss, and other diseases and disorder that limit an individual's capacity in biting, chewing, smiling, speaking and psychosocial wellbeing. Oral hygiene determines the oral health status of an individual. Poor oral hygiene is a risk factor for various oral disease which can be prevented by maintaining good oral hygiene. ${ }^{1}$ Oral hygiene is the practice of keeping the mouth clean and healthy by preventing the building plaque, the sticky film of bacteria and food that forms on teeth. Techniques of oral hygiene includes proper brushing, flossing, Proper rinsing after every meal, use of fluoridated toothpaste, drinking fluoridated water, and regular dental checkup. Maintaining oral hygiene should be a lifelong habit. ${ }^{2}$ Poor oral hygiene is determined by various factors such as mother's education, parental smoking practices, oral health behavior, oral hygiene level, dietary habits, and are shaped by broader socioeconomic and sociodemographic condition. The most of the common oral disease can be controlled only if the individual patient takes initiative for the prevention of the improper oral hygiene practices. ${ }^{3}$ Globally oral health is a major public health problem affecting a large number of people. Approximately $5-10 \%$ of public health expenses relate to oral health. It has a high economic burden in developed countries as well 
as in developing countries. Oral health problems are often neglected and only treated if pain or another problem arises. The prevalence of dental decay worldwide is $60-90 \%$ in school children. The incidence of oral cancer ranges from 1 to 10 cases per 1,000,000 populations in most countries. ${ }^{4}$ Dental caries (cavities) are the most common form of oral disease known to man, and the process of getting caries is called tooth decay.

Health education scientists have prepared very effective models by using different psychological and social patterns. One of these models is Health Belief Model (HBM), which was developed in 1950 by Hochbaum and Rosenstock. HBM is one of the most widely used in the public health to understand health behavior and plan a successful educational intervention. ${ }^{5}(\mathrm{HBM})$ is one of the first theories concerned with the health-related behaviors. It provides specific guidance at micro level for planning interventions for behavior change and now it is one of the most popular models in health education and promotion. Because of its dominant emphasis on prevention, it usually is applied in health protection activities. HBM is used to predict and explain behavioral changes in dental health and contains five main constructs: perceived susceptibility, perceived severity, perceived benefits, perceived barriers, and self-efficacy. ${ }^{6}$ General objective of the study was to identify the status of oral hygiene practices, its associated factors, and evaluate the effectiveness of oral health education package in improving the practices on oral hygiene among lower secondary school students of Bajrabarahi Municipality.

\section{Research hypothesis}

Research hypothesis for the interventional study is given below:

H0: There will be no significant improve in knowledge, practices and health belief on oral hygiene after the oral health education package.

H1: There will be significant increase in knowledge, practices and health belief on oral hygiene.

\section{Study variables}

\section{Variables for baseline study}

\section{Dependent variable}

Existing oral hygiene practices of the participant

\section{Independent variable}

Socio-demographic Factors:
I. Age
II. Sex
III. Ethnicity
IV. Religion

V. Father's education and occupation

VI. Mother's education and occupation.

\section{Source of information}

I. Existing knowledge on oral hygiene

II. Perceived susceptibility of dental caries

III. Perceived severity due to dental caries

\section{Perceived benefit of maintaining oral hygiene practices}

V. Perceived Barrier for maintaining oral hygiene practices.

\section{Variables for intervention study}

\section{Intervening variable}

Intervening variable for intervention study is health education package on oral hygiene.

\section{Dependent variable}

Dependent variables for the intervention study are:

I. Knowledge on oral hygiene

II. Belief on oral hygiene

III. Perceived susceptibility of dental caries

IV. Perceived severity due to dental caries

V. Perceived benefit of maintaining oral hygiene practices

VI. Perceived Barrier for maintaining oral hygiene practices

VII. Oral hygiene practice

\section{Conceptual framework of the study}

\section{Conceptual framework for the baseline study}

\section{Conceptual framework of the overall study}

Conceptual framework for the oral hygiene practice its associated factors Figure 1, evaluation of health education package is shown in Figure 2 which is adopted from health belief model. In the above framework the factors like socio demographic factors, knowledge, perceived susceptibility, severity, benefit, and barrier are independent variables of the study which are directly associated with the dependent variable i.e. existing oral hygiene practices. The framework helps to identify whether there is relation between these factors and oral hygiene practices. Framework also illustrate the relation between existing oral hygiene practice and oral health education package. After identification of the status of oral hygiene practice effective health education package is designed and implemented. Oral health education package is effective in increasing knowledge, perceived severity, susceptibility, benefit, barrier which ultimately leads to improving oral hygiene practices among the participants.

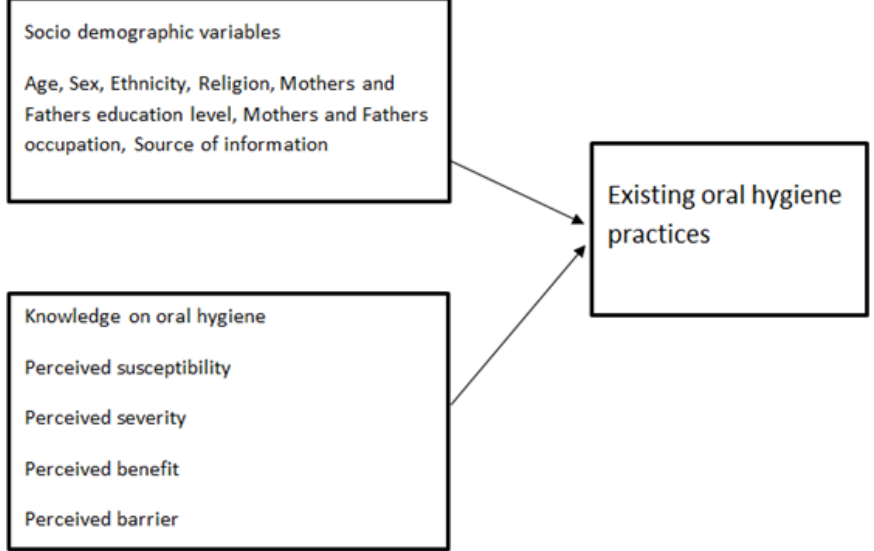

Figure I Conceptual framework of the study. 


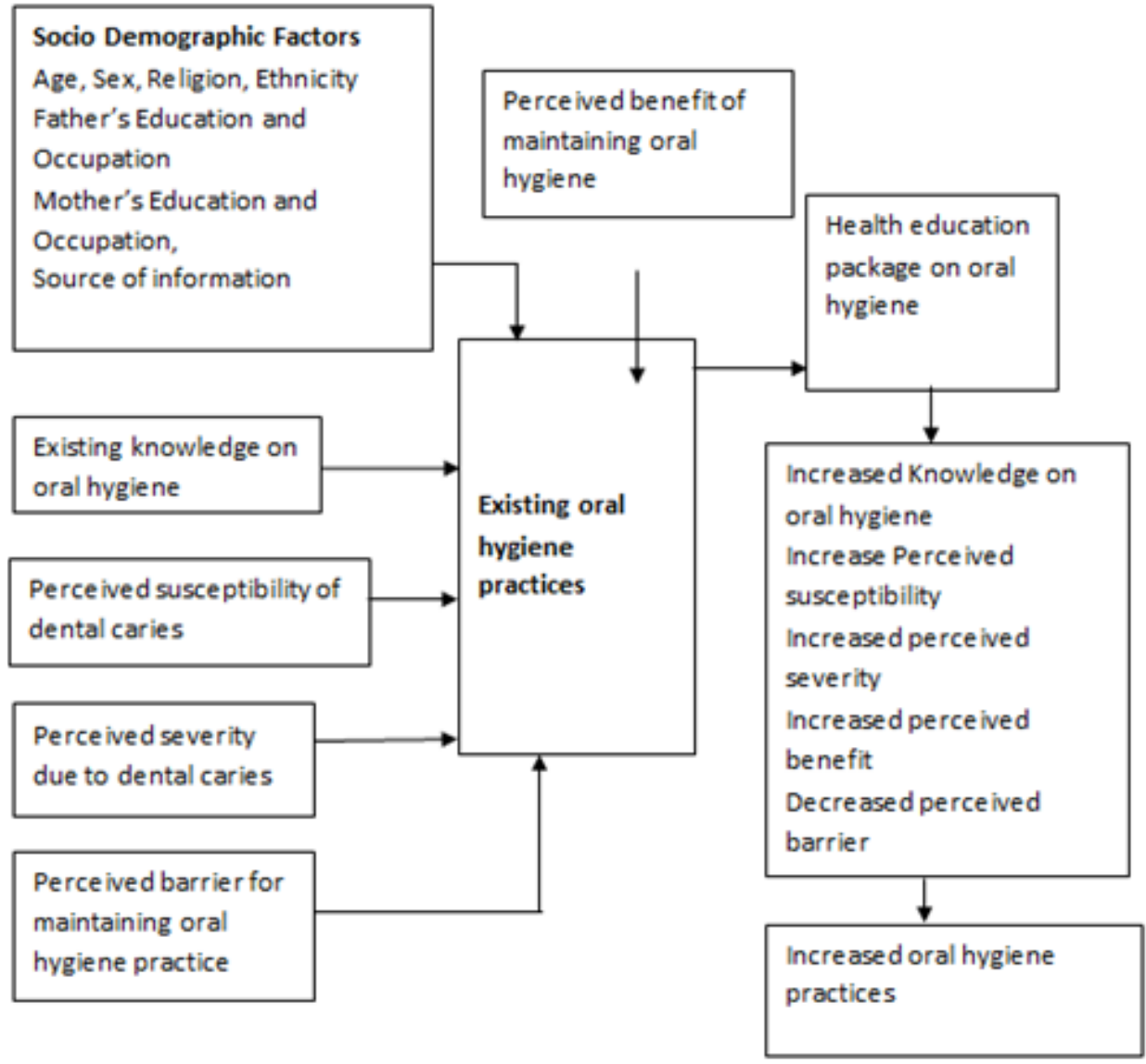

Figure 2 Conceptual framework of overall study.

\section{Methodology}

\section{Flow chart of the study}

The study was completed in 3 phases and each phase of the study had its own methodology in the study.

Phase I. Baseline study: In this phase the existing practice on oral hygiene and its associated factors on oral was identified among private school students of grade 6 to 8 .

Phase II. Education package design: In this phase according to the findings of the baseline study education package was designed.

Phase III. Implementation and evaluation of the package: In this phase the implementation of the package and assessment of its effectiveness was done (Figure 3 ).

\section{Phase I (Baseline study)}

\section{Study population}

Students of private secondary school of grade 6-8 of Bajrabarahi Municipality the study population of my study.

\section{Study site}

Study was conducted in Bajrabarahi Municipality of Lalitpur District. Bajrabarahi Municipality is Located in Sourthen Part of the Lalitpur Distict. Similar study has not been conducted in this area and the study site is feasible for the researcher in terms of time and distance.

\section{Sampling frame}

The sampling frame was List of private secondary schools in Bajrabarahi Municipality which was obtained from the District Education Office, Kathmandu. There were total 24 Seconday School in Bajrabarahi municipality.

\section{Sampling unit}

Primary sampling unit was schools and secondary sampling unit was 6-8 grade students.

\section{Study design}

Cross sectional study design for baseline study.

\section{Study method}

Study method for baseline study was Quantitative method. Quantitative study was conducted identify the status of oral hygiene practice, and its associated factors through the self-administered questionnaire.

\section{Tools and techniques of data collection}

Structure pretested self-administered questionnaire was used for data collection. A draft of questionnaire was develop on the basis of previous studies related to oral hygiene knowledge, practice and belief on HBM constructs. To assess the health belief on HBM constructs, the likert scale item were developed following the relevant previous studies. The questionnaire contains 10 question related to socio demographic variable, 11 question related to knowledge, 9 question 
related to practice, 3 question related to perceived susceptibility, 3 question related to perceived severity, 3 question related to perceived benefit, 4 question related to perceived barrier. The questionnaire was translated into Nepali language and pretesting of the questionnaire was done in class nine of Somang Academy of Bajrabarahi Municipality. After pretesting necessary changes were made. The same question was used for the post test and the post test data was collected four weeks after the intervention for both intervention and control group.

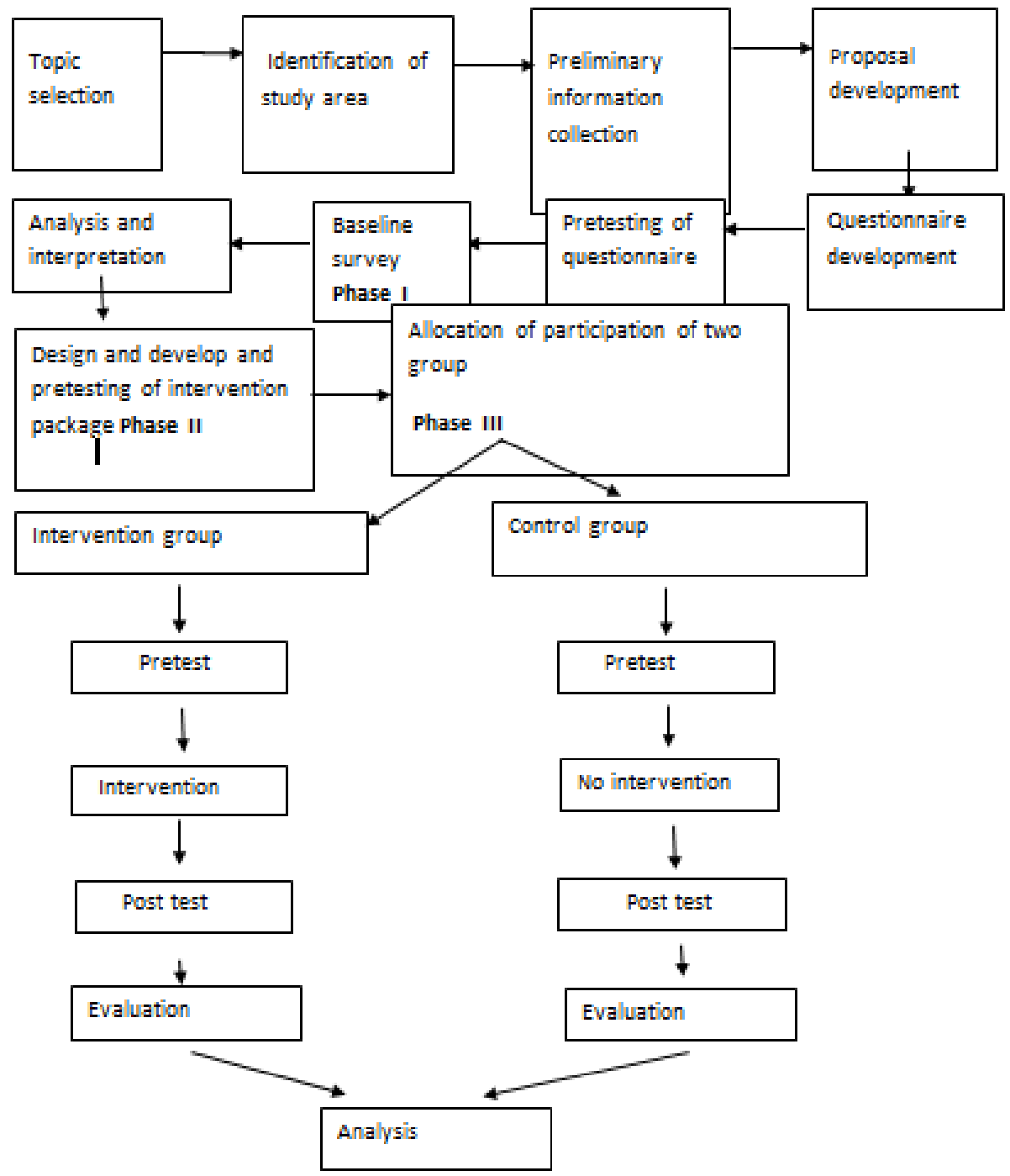

Figure 3 Flow chart of the study.

\section{Sample size (for baseline study)}

Formulae $\mathrm{n}=$ D.eff $\mathrm{Z}^{2} \mathrm{pq} / \mathrm{d}^{2}$

Where,

Design effect will be 1.75

$z=1.96$ $(0.39)$

Considering prevalence of oral hygiene practice $(\mathrm{P})=39 \%$

$$
\mathrm{q}=1-\mathrm{p}=0.5
$$

$\mathrm{d}=7 \%=0.07$ So, $(\mathrm{n})$ total sample for baseline study was 326 students.

\section{Sampling technique for baseline study}

Bajrabarahi Municipality was selected as study area then the list of the private school was obtained from the District Education Office
(DEO) of Latitpur. Then the random selection of the private school of Bajrabarahi Municipality was done according to the sample. Finally the cluster sampling of grade $6,7,8$ was done. According to the sample size 5 school was chosen randomly for the baseline study (Figure 4).

\section{Baseline data collection}

Data collection was conducted by the researcher herself. The baseline data was collected during the month of October. Selfadministered questionnaire was used to collect the baseline information. Data collection was conducted in five school of Bajrabarahi Municipality among all the students of grade 6-8.

\section{Pretesting of the tools}

Pretesting of the tools was carried out among the class 9 of Somang Academy of Bajrabarahi Municipality which was not selected for the study. After the pretesting, necessary changes and modification were done. For questions based on HBM constructs, Cronbach alpha was calculated which were above 0.6 for all subscale. 


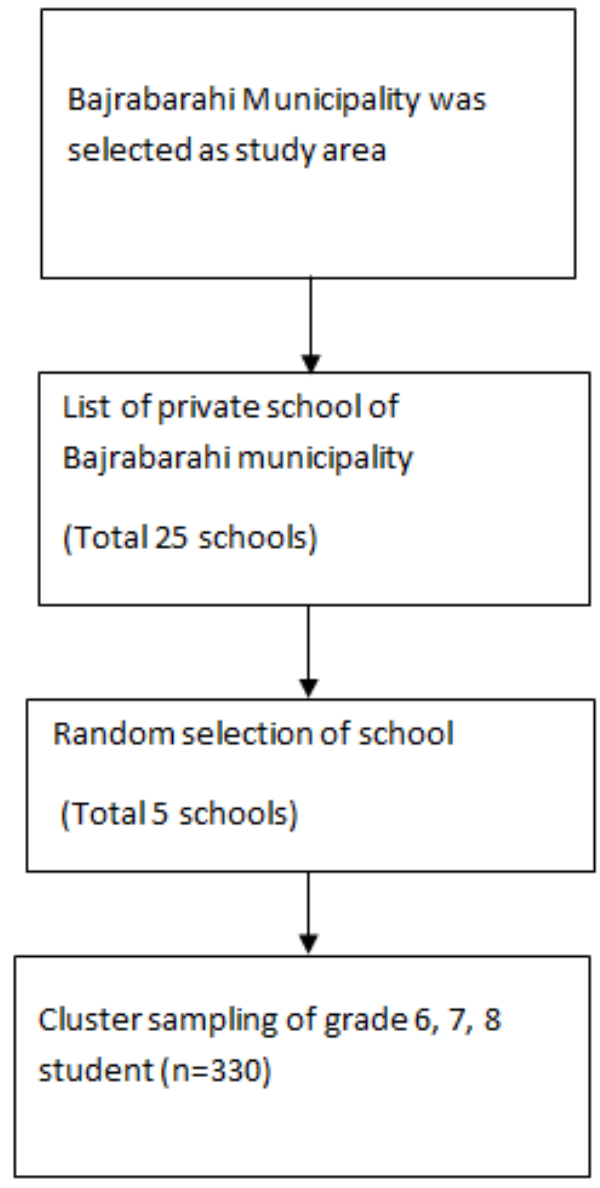

Figure 4 Sampling technique for baseline study.

\section{Data management and statistical analysis}

\section{For quantitative study}

The filled questionnaire was checked for its completeness, correctness \& internal consistency. Data editing was done immediately. Collected data was checked, edited manually by the researcher in the same day of data collection. Data was entry and analysis was done in (IBM SPSS) 21 version. Data was presented in the form of number, percentage, mean and standard deviation. Bivariate analysis was performed to test the existence of significant association between oral hygiene practice with age, sex, ethnicity, religion, education level of father and mother. P-value of $<0.05$ was considered to be significant where confidence interval (CI) for odds ratio (OR) was set for $95 \%$. Independent test was used to show the association between HBM constructs and oral hygiene practice.

\section{Phase II: Education package development for oral hygiene practice}

In this phase, the information collected in the first phase was utilized. On the basis of finding of the first phase the oral health education package was designed. Steps includes:

Step 1: Analysis

Step 2: Strategic Design

Step 3: Development and Testing

Step 4: Implementation
Step 5: Evaluation and Monitoring

\section{Phase III (Intervention study)}

The objective of this phase is to implement the educational package on the intervention group and evaluate the effectiveness of the intervention package among intervention and control group.

\section{Research design for intervention}

Quasi Experimental pre-test post-test control design was applied for intervention study

\begin{tabular}{llll}
\hline School & Pre test & Intervention & Post test \\
\hline Intervention school & OI & $X$ & O2 \\
Control school & $\mathrm{O} 3$ & & 04
\end{tabular}

\section{Study area}

The study area was Bajrabarahi Municipality of Lalitpur district.

\section{Study population}

Students of grade 6-8 of private school of Bajrabarahi municipality.

\section{Sampling technique}

For the intervention study from the total 5 school of the baseline study 2 school is selected randomly as intervention school which consist of 118 students and 3 school was randomly selected as control school which consists of 212 students (Figure 5).

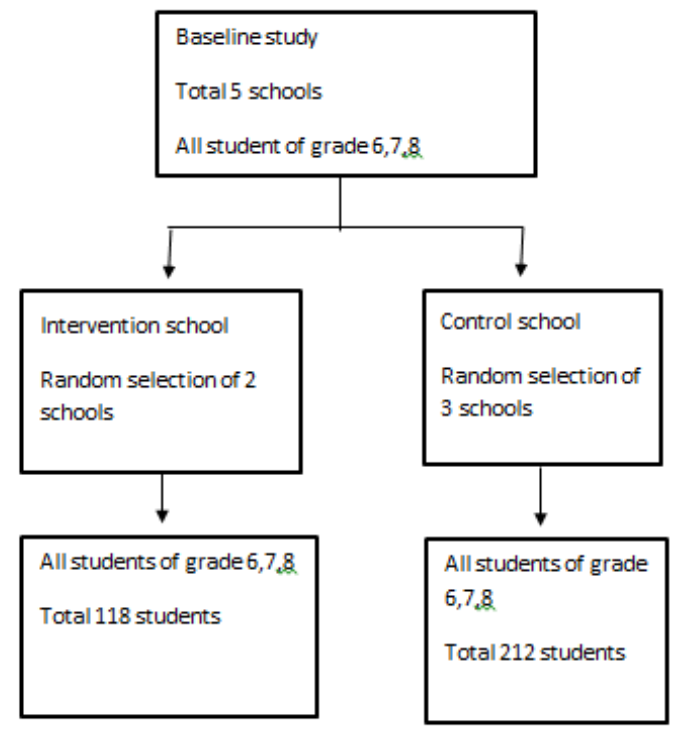

Figure 5 Sampling technique for baseline study.

\section{Data collection tools and techniques}

Post test was conducted after 1 month of the implementation of intervention package in both the intervention and control group. Selfadministered question which was used for the pretest in the baseline study was used to assess the knowledge, practice, health belief on oral hygiene.

\section{Data collection}

Data collection was conducted by the researcher herself. Posttest data collection was conducted 1 month after the intervention. It was conducted on poush 16 and 17. 


\section{Data processing and analysis}

Data was entry and analysis was done in IBM SPSS (version 21). Pre-test and post test data was analyzed using descriptive analysis to assess change in the variables. Difference in intervention and control group regarding knowledge, HBM constructs and practice score was compared by applying Mann Whitney U test.

\section{Validity and reliability of the study}

Validity Questionnaire was prepared through extensive literature review with guidance and support from supervisors. Researcher herself was involved in data collection, analysis and intervention. External validity was ascertained by random sampling and obtaining an adequate sample size and internal validity was ensured by constructing questionnaire using standardized tool.

Reliability Translation and back translation of the tools (English and Nepali) was carried out and peer reviewed. Questionnaire was finalized in Nepali language and in simple to understand form. Data collection tools was pre-tested in class 9 of Somang Academy. Internal consistency of the questions on constructs of HBM with Likert scale was assessed using 'Cronbach's alpha ( $\alpha)$ '. The obtained value of $\alpha$ for each constructs was greater than 0.6 which was found to be adequate. Researcher was directly engage in data collection, cross-checking, data entry, processing and analysis. Each filled questionnaire was rechecked just after completing the data collection so that any missed/ under responding could be corrected. The result of the study was verified with relevant literature.

\section{Duration of the study}

Duration of the study is 9 month from Asadh till Falgun. Data collection period was from Asoj to Poush including baseline study and interventional study.

\section{Limitation of the study}

Long term impact of intervention on students' knowledge, attitude and practice could not be assessed. Study will be carried out in school setting. So, the findings couldn't be generalized to other settings. The time gap between the intervention and posttest was only 1 month.

\section{Ethical consideration}

Ethical clearance was taken from Institutional Review Board (IRB) at Institute of Medicine to undertake the study. The approval letter introducing researcher and stating study objectives and methodology was taken from Department of Community Medicine and Public Health, Maharjgunj Medical Campus. Permission letter was taken from District Education Office Lalitpur and letter was shared with the principal of the school. The study objectives was clearly shared with the school authorities, respondents and parents and written consent was taken from all. All were made assured about confidentiality to be maintained throughout study. Participants was explained about the study and they were pre-informed that they may not take part at all after knowing about the study or they might choose not to answer to any specific question or they might quit the interview at any time without giving any reason for it and no force would be applied to take part or continue or answer the questions they don't wanted to. There were some of the student who were suffering from dental problems and toothache during my study. Hence the objective of the study was not to urgently help the student with oral health problem. So, researcher informed in the classroom that those who have some problem regarding oral health must go to the dentist and get treated, otherwise they might get serious oral health problems.

\section{Results}

This study was conducted to identify factors associated to oral hygiene practices and evaluation of health education program on oral hygiene. This chapter deals the findings and analysis of the study. The first part of the result section includes the result obtained from the baseline study which includes socio demographic characteristics and the factors associated to oral hygiene practices of the study population. The second part of this chapter includes the development of oral health education package. Finally third phase includes descriptive analysis and hypothesis testing of experimental study and the result obtained from evaluation of pretest posttest between intervention and control group.

\section{Phase I: Descriptive analysis}

\section{Socio demographic characteristics of the student}

Table one represents the socio demographic characteristics of the student. A total 330 student completed the questionnaire. The age of the student ranged from 10 years to 16 years with mean age is 12.65 years. The percentage of male and female was 47.6 and 52.4 respectively. The ethnicity of the majority of the respondents were Janajati 56.8 percent followed by Brahmin 19.6 percent and Chhetri 14.8 percent. Majority of the student were Hindu 74.9 percent followed by Christian 13.3 percent. Regarding education level of the parents, majority of the mother of the respondents were illiterate 82.1percent illiterate. Regarding the education level of the father, majority 88.8 percent are literate. Regarding the occupation, most of the mothers are house maker 28.1 percent followed by business 27.5 percent. Occupation of the 47.6 percent of the father was service followed by business which was 30.5 percent. The major source of information of the students 45.2 percent and radio and television is another source of information 28.2 percent.

\section{Knowledge on oral hygiene}

The participant's knowledge about oral hygiene is presented in table 2. Most of the participants responds that they should brush their teeth $(88.2 \%)$. Regarding knowledge on material for cleaning teeth majority responds that they should use toothpaste and toothbrush for cleaning $(86.1 \%)$. Regarding knowledge on frequency of brushing $(71.2 \%)$ think that they should brush twice a day. Maximum number of participants responds that they should brush their teeth after meal $(64.5 \%)$. Only $36.1 \%$ participants have knowledge on proper techniques of brushing. Regarding the knowledge on rinsing mouth majority $(62.4 \%)$ response that they should rinse their mouth after every meal (62.4\%). Regarding knowledge on visiting dentist (24.2\%) responses that they should visit every 6 month.

Table I Socio demographic characteristics $(n=330)$

\begin{tabular}{llll}
\hline Characteristics & Category of variable & Number & Percentage (\%) \\
\hline Age (years) & 12-Oct & 161 & 48.8 \\
& $13-16$ & 169 & 51.2 \\
Mean age (years) & 12.65 & & \\
\hline
\end{tabular}




\begin{tabular}{|c|c|c|c|}
\hline Characteristics & Category of variable & Number & Percentage (\%) \\
\hline \multirow[t]{2}{*}{ Sex } & Male & 157 & 47.6 \\
\hline & Female & 173 & 52.4 \\
\hline \multirow[t]{5}{*}{ Ethinicy } & Brahmin & 65 & 19.6 \\
\hline & Chhetri & 48 & 14.8 \\
\hline & Janajati & 188 & 56.8 \\
\hline & Madhesi & 20 & 7.8 \\
\hline & Others & 9 & 0.9 \\
\hline \multirow[t]{4}{*}{ Religion } & Hindu & 247 & 74.9 \\
\hline & Buddhist & 28 & 8.5 \\
\hline & Christian & 44 & 13.3 \\
\hline & Other & 11 & 3.3 \\
\hline Education level & Literate & 271 & 17.9 \\
\hline of mother & Illiterate & 59 & 82.1 \\
\hline \multirow[t]{3}{*}{ Education of father } & Literate & 291 & 88.8 \\
\hline & Illiterate & 39 & 11.2 \\
\hline & Agriculture & 59 & 17.8 \\
\hline \multirow[t]{2}{*}{ Occupation of mother } & Business & 91 & 27.5 \\
\hline & Service & 87 & 26.6 \\
\hline \multirow[t]{5}{*}{ Occupation of father } & House maker & 93 & 28.1 \\
\hline & Agriculture & 27 & 8.2 \\
\hline & Business & 101 & 30.6 \\
\hline & Service & 157 & 47.6 \\
\hline & Foreign country & 45 & 13.6 \\
\hline Major Source of information & radio/TV & 93 & 28.2 \\
\hline \multirow[t]{3}{*}{ on oral hygiene } & Friends & 7 & 2.1 \\
\hline & Family & 149 & 45.2 \\
\hline & Teachers & 81 & 24.5 \\
\hline
\end{tabular}

Table 2 Knowledge on oral hygiene $(n=330)$

\begin{tabular}{|c|c|c|c|}
\hline Characteristics & Category of variable & Number & Percentage \\
\hline \multirow[t]{2}{*}{ Should one brush teeth } & Yes & 291 & 88.2 \\
\hline & No & 39 & 11.8 \\
\hline \multirow[t]{2}{*}{ Material for cleaning teeth } & Toothpaste and toothpaste & 284 & 86.1 \\
\hline & Other material & 46 & 13.9 \\
\hline \multirow[t]{2}{*}{ Frequency of brushing } & Once & 95 & 28.8 \\
\hline & Twice & 235 & 71.2 \\
\hline \multirow[t]{2}{*}{ Time of brushing } & Before meal & 117 & 35.2 \\
\hline & After meal & 213 & 64.5 \\
\hline \multirow[t]{2}{*}{ Appropriate technique of brushing } & Appropriate technique & 119 & 36.1 \\
\hline & Inappropriate technique & 211 & 63.9 \\
\hline \multirow[t]{2}{*}{ How often should one rinse their mouth } & After major meal of morning and evening & 124 & 37.6 \\
\hline & After every meal & 206 & 62.4 \\
\hline \multirow[t]{2}{*}{ How often should one visit a dentist } & Every 6 month & 80 & 24.2 \\
\hline & $>6$ month(whenever there is problem) & 250 & 75.8 \\
\hline
\end{tabular}

Citation: Poudel R, Chalise B. Oral hygiene practices, its associated factors and evaluation of oral health education package among 6-8 grade students of bajrabarahi municipality, Lalitpur. Int J Fam Commun Med. 202I;5(2):45-58. DOI: I0.I5406/ijfcm.202I.05.00220 


\section{Overall score on knowledge on oral hygiene}

Table 3 represent the overall knowledge score on oral hygiene. $85.2 \%$ of the respondent have knowledge above or equal average and $14.8 \%$ of the respondent have knowledge below average with mean 4.87 and standard deviation 1.43 (Table 3 ).

Table 3 Overall score on knowledge $(n=330)$

\begin{tabular}{lllll}
\hline $\begin{array}{l}\text { Overall score on oral } \\
\text { hygiene knowledge }\end{array}$ & Number & $\begin{array}{l}\text { Percentage } \\
(\%)\end{array}$ & Mean & S.D \\
\hline Above or equal average & 281 & 85.2 & 4.87 & 1.43 \\
Below average & 49 & 14.8 & & \\
\hline
\end{tabular}

\section{Oral hygiene practices}

Regarding tooth brushing practices, among the total respondents, $100 \%$ of the respondents brush their teeth. Among all 330 respondents who brush their teeth daily, (37.6\%) of the student brush their teeth twice a day. Among all the respondents majority (81\%) of responses that they use toothpaste and toothbrush to clean their teeth. Only $54 \%$ of the respondent change their toothpaste more than 6 month. Among the participants $23.9 \%$ followed the appropriate technique of brushing. Maximum participants 55\% used to rinse their mouth after major meal and $45 \%$ rinse their mouth only after major meal. Maximum participants $73.4 \%$ used to visit dentist. Among the participant who visit dentist only $20.2 \%$ visit every 6 month Table 4 .

Table 4 Oral hygiene practice $(n=330)$

\begin{tabular}{|c|c|c|c|}
\hline Characteristics & Category of variable & Number & Percentage (\%) \\
\hline Practice of brushing & Yes & 130 & 100 \\
\hline \multirow[t]{2}{*}{ Frequency of brushing in a day } & Once & 206 & 62.4 \\
\hline & Twice & 124 & 37.6 \\
\hline \multirow[t]{3}{*}{ Materials for cleaning teeth } & Toothbrush and toothpaste & 265 & 81 \\
\hline & Toothpowder & 50 & 15 \\
\hline & Neemstick & 15 & 5 \\
\hline \multirow[t]{3}{*}{ Frequency of change of toothbrush } & When it flares & 18 & 6 \\
\hline & Every 3-6 month & 132 & 40 \\
\hline & More than 6 month & 180 & 54 \\
\hline \multirow[t]{2}{*}{ Technique of brushing } & Appropriate technique & 79 & 23.9 \\
\hline & Inappropriate technique & 251 & 76.1 \\
\hline \multirow[t]{2}{*}{ Frequency of rinsing } & After every meal & 205 & 45 \\
\hline & After major meal & 125 & 55 \\
\hline \multirow[t]{2}{*}{ Practice of visiting dentist } & Yes & 242 & 73.4 \\
\hline & No & 88 & 26.5 \\
\hline \multirow[t]{3}{*}{ Frequency of visiting dentist } & When there is problem in teeth & 93 & 38.2 \\
\hline & Every 6 month & 49 & 20.2 \\
\hline & More than 6 month & 100 & 41.3 \\
\hline
\end{tabular}

\section{Status of oral hygiene practices}

Regarding the status of oral hygiene practice more than fifty percent of the participant have below average practice on oral hygiene $(55.8 \%)$ and only $44.2 \%$ of the participant have above average practice on oral hygiene. The mean scoring of oral hygiene practice is 3.34 and S.D is 1.14 Table 5.
Health beliefs on oral hygiene based on Health Belief Model constructs

The individual health belief were measured using the questionnaire based on health belief model which was on Likert's scale items. The mean and standard deviation for each item are presented in the Table 6,7 .

Table 5 Status of oral hygiene practice $(n=330)$

\begin{tabular}{lllll}
\hline Overall score on oral hygiene practice & Number & Percentage (\%) & Mean & S.D \\
\hline Above or equal average & 146 & 44.2 & 3.34 & 1.14 \\
Below average & 184 & 55.8 & & \\
\hline
\end{tabular}


Table 6 HBM constructs on oral hygiene practices $(n=330)$

\begin{tabular}{lll}
\hline Constructs & Mean & St deviation \\
\hline Perceived susceptibility & 8.65 & 1.66 \\
Perceived severity & 9.97 & 2.5 \\
Perceived benefit & 11.93 & 2.1 \\
Perceived barrier & 10.68 & 3.57 \\
\hline
\end{tabular}

Table 7 Association of oral hygiene practice with socio demographic variables $(n=330)$

\begin{tabular}{|c|c|c|c|c|c|}
\hline \multirow[t]{2}{*}{ Variables } & \multicolumn{2}{|l|}{ Oral hygiene practices } & \multirow[t]{2}{*}{ Odds Ratio } & \multirow[t]{2}{*}{$95 \% \mathrm{Cl}$} & \multirow[t]{2}{*}{$P$ value } \\
\hline & Above or equal average (\%) & Below av & & & \\
\hline \multicolumn{6}{|l|}{ Age } \\
\hline $12-O c t$ & $77(47.5)$ & $85(52.5)$ & 1.3 & $0.8-2.0$ & 0.2 \\
\hline $13-14$ & $69(4 I .1)$ & $99(58.9)$ & Ref & & \\
\hline \multicolumn{6}{|l|}{ Sex } \\
\hline Male & $64(40.8)$ & $93(59.2)$ & 0.7 & $0.4-I . I$ & 0.7 \\
\hline Female & $82(47.4)$ & $91(52.6)$ & Ref & & \\
\hline \multicolumn{6}{|c|}{ Education of mother } \\
\hline Literate & $128(47.2)$ & $143(52.8)$ & 2 & I.II-3.7 & $0.01 *$ \\
\hline Illiterate & $18(30.5)$ & $4 I(69.5)$ & Ref & & \\
\hline \multicolumn{6}{|c|}{ Education of father } \\
\hline Literate & $129(44.3)$ & $162(55.7)$ & 1 & $0.5-2.0$ & 0.9 \\
\hline Illiterate & $17(43.6)$ & $22(56.4)$ & Ref & & \\
\hline
\end{tabular}

Association of oral hygiene practice with socio demographic variables

Bivariate analysis was done to find out association of oral hygiene practices with different socio demographic variables using chi-square test which is shown in table 7. Education level of mother was found significantly associated with oral hygiene practice. Students whose mothers are literate are 2 times more likely $(\mathrm{OR}=2, \mathrm{CI}=1.11-3.7)$ to maintain the oral hygiene than the students whose mother are illiterate Table 8 \& 9 .

Table 8 Association of oral hygiene practice with socio demographic variables $(n=330)$

\begin{tabular}{|c|c|c|c|c|}
\hline \multirow[t]{2}{*}{ Variables } & \multicolumn{2}{|l|}{ Oral hygiene practices } & \multirow{2}{*}{$\begin{array}{l}\text { P value } \\
\text { age }\end{array}$} & \multirow[t]{2}{*}{$95 \% \mathrm{Cl}$} \\
\hline & Above or equal average & Below average & & \\
\hline \multicolumn{5}{|c|}{ Occupation of mother } \\
\hline Agriculture & $26(44.1)$ & $33(55.9)$ & 0.5 & $0.5-1.9$ \\
\hline Business & $36(39.1)$ & $56(60.9)$ & & \\
\hline Service & $43((50.0)$ & $43(50.0)$ & & \\
\hline Housemaker & $4 I(44.1)$ & $52(55.9)$ & & \\
\hline \multicolumn{2}{|c|}{ Occupation of father } & & 0.2 & $0.2-1.7$ \\
\hline Agriculture & $15(56.6)$ & I2(44.4) & & \\
\hline Business & $37(36.6)$ & $64(63.4)$ & & \\
\hline Service & $74(46.8)$ & $84(53.2)$ & & \\
\hline Foreign country & $20(45.5)$ & $24(54.5)$ & & \\
\hline
\end{tabular}

Citation: Poudel R, Chalise B. Oral hygiene practices, its associated factors and evaluation of oral health education package among 6-8 grade students of bajrabarahi municipality, Lalitpur. Int J Fam Commun Med. 202I;5(2):45-58. DOI: I0.I5406/ijfcm.202I.05.00220 
Table 9 Association of oral hygiene practice with knowledge $(n=330)$

\begin{tabular}{|c|c|c|c|c|c|}
\hline Variables & Oral hygiene practices & & Odds ratio & $95 \% \mathrm{Cl}$ & $P$ value \\
\hline Knowledge on oral hygiene & Above or equal mean & Below mean & & & \\
\hline Above or equal mean & $126(44.7)$ & $156(55.3)$ & 1.13 & $0.6-2.1$ & 0.6 \\
\hline Below mean & $20(4 I .7)$ & $28(58.3)$ & REF & & \\
\hline
\end{tabular}

\section{Association of oral hygiene practice with knowledge}

Association of oral hygiene practice with health belief model constructs

The association of oral hygiene practice with HBM constructs, perceived susceptibility, perceived severity, perceived benefit, and perceived barrier Table 10

Table 10 Association of Oral hygiene practice with health belief mode constructs

\begin{tabular}{|c|c|c|c|c|}
\hline \multirow[t]{3}{*}{ Variables } & \multicolumn{2}{|c|}{ Oral hygiene practices } & \multirow[t]{2}{*}{$95 \% \mathrm{Cl}$} & \multirow[t]{2}{*}{$P$ value } \\
\hline & Mean \pm SD & & & \\
\hline & $\begin{array}{l}\text { Above } \\
\text { or equal } \\
\text { average }\end{array}$ & $\begin{array}{l}\text { Below } \\
\text { average }\end{array}$ & & \\
\hline $\begin{array}{l}\text { Perceived } \\
\text { susceptibility }\end{array}$ & $8.7 \pm 1.73$ & $8.5 \pm 1.6$ & -0.6 & 0.1 \\
\hline $\begin{array}{l}\text { Perceived } \\
\text { severity }\end{array}$ & $9.9 \pm 2.4$ & $10.02 \pm 2.5$ & -1 & 0.5 \\
\hline $\begin{array}{l}\text { Perceived } \\
\text { benefit }\end{array}$ & $11.8 \pm 2.03$ & $12.02 \pm 2.15$ & -0.83 & 0.8 \\
\hline $\begin{array}{l}\text { Perceived } \\
\text { barrier }\end{array}$ & $10.69 \pm 3.14$ & $10.67 \pm 3.88$ & -1.4 & $0.01 *$ \\
\hline
\end{tabular}

\section{Phase II: Development of oral health education package}

Oral health education package was developed in this phase following the various steps. Process of Package development includes:

\section{Step 1: Situation analysis}

Baseline study was done in five secondary schools of Bajrabarah Municipality of Lalitpur district among 6-8 grade student to identify the Knowledge, belief and practice on oral hygiene. On the basis of the findings, it's concluded that: $36 \%$ of the participant have knowledge on appropriate technique of brushing. Regarding practice on oral hygiene only $37.6 \%$ of the participant brush their teeth twice a day and only $23.9 \%$ followed the appropriate technique of brushing. $44.2 \%$ have above or equal average score on oral hygiene practice. The study shows that there is significant association between oral hygiene practice and perceived barrier of the student. KII with health teacher and informal interaction with students of the intervention school was conducted for methods and media analysis and according to their preference poster and demonstration on appropriate technique of brushing was designed.

\section{Step 2: Strategic design}

Every communication or awareness program or package needs a strategic design. It involves: Establishing objectives, determining method/media, draw up an implementation plan (schedule) and evaluation plan. HBM constructs was chosen as behavior change model. The content of the awareness package was focused on increasing the participant's perceived susceptibility and severity of oral health problems, increasing the perception of benefit of proper oral hygiene practices and decreasing their perception of barrier. Message was designed according to the appropriate analysis of the methods, media and audiences. For the methods and media analysis in-depth interview with the health teacher and informal interaction with the students was conducted to identify their preferences of methods and media of the intervention school. According to their preference demonstration on toothbrushing was choosen as the method for health education and poster on appropriate technique of brushing was choosen as media. Objectives of oral health education package. The objective of this phase is to develop the oral health education package based on the findings of the baseline study and to provide the knowledge and health education on oral hygiene practice.

Contents for the oral health education package includes:

I. Introduction on oral hygiene

II. Different oral health problems

III. Various techniques of oral hygiene

IV. Perceived susceptibility, perceived severity, perceived benefit, perceived barrier regarding oral hygiene practices

V. Detail explanation on brushing, rinsing, regular dental checkup

VI. Demonstration on proper technique of brushing.

\section{Step 3: Development and testing}

On the basis of situation analysis, necessary content of oral health education package was developed to administer in intervention group. This content was tested on similar group (grade 7 of Indreni Higher Secondary School, Bajrabarahi) and necessary modification of the contents was done that were not understood correctly by the students.

\section{Step 4: Implementation and monitoring}

Package was implemented among the intervention group. As per the plan it was held on 1st week of Poush. One Day session of oral health education package was implemented in intervention group which was delivered by the researcher herself. Chart papers, posters, toothbrush were used as a media. Lecture, demonstration and discussion was the methods used for the health education. During the session at first students were introduced about what is oral hygiene, importance of oral hygiene practices. The content was based on the HBM constructs. Demonstration on proper technique of brushing was done. The detail intervention plan is attached in the annex.

\section{Implementation plan}

Implementation plan for the health education session is present in the Table below. 


\begin{tabular}{lll}
\hline Duration & Content & Methods and media \\
\hline $15 \mathrm{~min}$ & Introduction on oral hygiene & Discussion/chat papers \\
$20 \mathrm{~min}$ & Oral health problems due to poor oral hygiene practices & $\begin{array}{l}\text { Discussion with mini lectures/chart } \\
\text { papers }\end{array}$ \\
$20 \mathrm{~min}$ & $\begin{array}{l}\text { Impacts of oral health problems on health and daily activities due to poor } \\
\text { oral hygiene practices }\end{array}$ & Mini lecture/chart papers \\
$20 \mathrm{~min}$ & Benefit of maintaining oral hygiene practices & Discussion with mini lectures/chart \\
$20 \mathrm{~min}$ & Techniques of oral hygiene practices & papers \\
$\mathrm{Half}$ an hour & Appropriate technique of tooth brushing & Discussion/chart papers \\
$15 \mathrm{~min}$ & Conclusion & Demonstration/Posters \\
\hline
\end{tabular}

\section{Step 5: Evaluation}

Evaluation of the education package was done in same of intervention day by asking questions to the students. For assessing the improvement in knowledge, belief, practice regarding the oral hygiene post-test was done after 1 month of delivering package in intervention school. Effectiveness of the oral health education package was assessed using the pretest posttest comparison among the intervention and control group.

\section{Phase III: Interventional study}

\section{Mean score comparison in intervention and control group}

Mean score comparison of knowledge, perceived susceptibility, perceived severity, perceived benefit and perceived barrier between pretest and posttest among intervention and control group is represented by Table 10, 11 .

Table II Mean score comparison in intervention and control group

\begin{tabular}{|c|c|c|c|c|}
\hline & \multicolumn{2}{|c|}{ Control $(\mathrm{N}=\mathbf{2} \mid \mathbf{2})$} & \multicolumn{2}{|c|}{ Intervention( $\mathrm{N}=|| 8)$} \\
\hline & Mean (SD) & & Mean(SD) & \\
\hline & Pretest & Posttest & Pretest & Posttest \\
\hline Knowledge & $4.30(1.32)$ & $4.55(1.16)$ & $4.05(I .31)$ & $5.93(0.96)$ \\
\hline Perceived susceptibility & $8.5(1.3)$ & $9.63(2.3)$ & $8.5(1.39)$ & $9.63(2.3)$ \\
\hline Perceived severity & -2.6 & II.32(2.40) & $8.57(1.80)$ & $9.04(2.18)$ \\
\hline Perceived benefit & $11.98(2.14)$ & $11.69(2.13)$ & $11.83(2.02)$ & $11.58(1.3)$ \\
\hline Perceived barrier & $10.75(3.69)$ & $12.26(3.24)$ & $10.55(3.35)$ & $10.59(2.4 \mathrm{I})$ \\
\hline
\end{tabular}

Comparison of oral hygiene practices in control and intervention group

Comparison of oral hygiene practice between intervention and control group and difference in percentage is compared among pretest and posttest. After the intervention appropriate technique of brushing increased from pretest $15.3 \%$ to posttest $57.1 \%$, the percentage change is shown $41.8 \%$ whereas practice of brushing twice a day increase from pretest $37.3 \%$ to posttest $73.9 \%$, the percentage change is shown $36.6 \%$. In control group the percentage change in appropriate technique of brushing is $7.6 \%$ whereas percentage change in brushing twice a day is $19.8 \%$ where there is no intervention was implemented Table 12.

Table I 2 Comparison of oral hygiene practices in control and intervention group

\begin{tabular}{|c|c|c|c|c|c|c|}
\hline \multirow[t]{3}{*}{ Practices } & \multicolumn{2}{|c|}{ Intervention } & \multirow[t]{2}{*}{ Change (\%) } & \multirow{2}{*}{\multicolumn{2}{|c|}{$\begin{array}{l}\text { Control } \\
(N=2 \mid 2)\end{array}$}} & \multirow[t]{3}{*}{ Change (\%) } \\
\hline & $(N=|| 8)$ & & & & & \\
\hline & Pretest & Posttest & & Pretest & posttest & \\
\hline Appropriate technique of brushing & $35(16.5)$ & $5 I(24 . I)$ & 7.6 & $18(15.3)$ & $68(57.1)$ & 41.8 \\
\hline Brushing twice a day after meal & $58(27.4)$ & $100(47)$. & 19.8 & $44(37.3)$ & $88(73.9)$ & 36.6 \\
\hline
\end{tabular}

\section{Hypothesis testing}

Hypothesis testing was done using Mann whitney U test as there were two independent samples and not normally distributed. The test measures the significant difference between intervention and control group in pretest and posttest. Hypothesis were as follows:

$\mathrm{H} 0$ : There will be not any significant increase in knowledge, belief and oral hygiene practices after intervention.
H1: There will be significant increase in knowledge, belief and oral hygiene practices after intervention.

\section{Difference in oral hygiene practice between intervention and} control group

Knowledge on oral hygiene, Perceived susceptibility, Perceived severity, Perceived benefit, perceived barrier day is significantly 
different in posttest in intervention and control group and it was not different in pretest score which is represent in Table 12,13.

\section{Difference in oral hygiene practices}

The Table 13 represents that the appropriate technique of brushing practice of brushing twice a day is significantly different in posttest in intervention and control group and it was not different in pretest score Table 14. To summarize the knowledge, perceived severity, susceptibility, benefit, barrier and oral hygiene practice is significantly different in posttest in intervention and control group and it was not different in pretest score hence the oral health education package is found to be effective.

Table I 3 Difference in oral hygiene practice between intervention and control group

\begin{tabular}{lllll}
\hline Variable & Groups & N & Pretest & Post test \\
\hline & & & (P value) & (P value) \\
\hline Knowledge on oral hygiene & Intervention & 118 & 0.1 & $<0.01 *$ \\
& Control & 212 & & \\
Perceived susceptibility & Intervention & 118 & 0.7 & $0.01^{*}$ \\
& Control & 212 & & \\
Perceived severity & Intervention & 118 & 0.7 & $<0.0)^{*}$ \\
& Control & 212 & & \\
Perceived benefit & Intervention & 118 & 0.4 & 0.2 \\
& Control & 212 & & \\
Perceived barrier & Intervention & 118 & 0.6 & $<0.01 *$ \\
& Control & 212 & & \\
\hline
\end{tabular}

Table I 4 Oral hygiene practices

\begin{tabular}{lllll}
\hline Variables & groups & N & Pretest (p value) & Posttest \\
\hline & & & & (p value) \\
\hline Appropriate technique of brushing & Intervention & 118 & 0.77 & $<0.0 I^{*}$ \\
& control & 212 & & \\
Practice of brushing twice a day after meal & intervention & 118 & 0.06 & $<0.0 I^{*}$ \\
& control & 212 & & \\
\hline
\end{tabular}

\section{Discussion}

The purpose of this study was to find out the status of oral hygiene practice, its associated factors and develop the oral health education package and assess its effectiveness. Status of oral health hygiene practice and its associated factors was assessed from baseline study in terms of knowledge about oral hygiene, perceived susceptibility, perceived severity, benefit and barrier. The health education package was developed based on these findings and the package was evaluated using the experimental study design.

\section{Oral hygiene practice}

Regarding tooth brushing practices, among the total respondents, $100 \%$ of the respondents brush their teeth. Among all 330 respondents who brush their teeth daily, (37.6\%) of the student brush their teeth twice a day. The finding was slightly higher than the study which was done in Oral Hygiene Status, Knowledge, Perceptions and Practices among School Settings in Nepal and rural South India. ${ }^{20,21}$ Among all the respondents majority of responses $(80 \%)$ use toothpaste and toothbrush to clean their teeth. Only $54 \%$ of the respondent change their toothpaste more than 6 month. The findings was found to be significant with the studies conducted in Bhaktapur. ${ }^{12}$ Regarding the status of oral hygiene practice more than fifty percent of the participant have below average practice on oral hygiene and only $44.2 \%$ of the participant have above average practice on oral hygiene. The mean scoring of oral hygiene practice is 3.34 and the study is similar to the study conducted in Ludhiana Punjab among the school children. ${ }^{4}$

\section{Knowledge on oral hygiene}

More than eighty percent of the participants responds that they should brush their teeth. Regarding knowledge on material for cleaning teeth majority responds that they should use toothpaste and toothbrush for cleaning $(86.1 \%)$. Regarding knowledge on frequency of brushing $(71.2 \%)$ think that they should brush twice a day. The study is similar with the study conducted in India and Iran. ${ }^{22,23}$ The study reveals that the oral hygiene practice is not adequate while in similar study majority of higher participant had good oral hygiene status. The findings was not consistent with the study of Nur-E -Saud et al. ${ }^{24}$ The oral health education package was found to be effective in intervention group. Knowledge and practice on oral hygiene was found to be increased after the health education. The study which was conducted in China Wuhan shows the similar results which shows that increase in knowledge, attitude and practice on oral hygiene after the oral health education. ${ }^{18,25}$ 


\section{Conclusion and recommendation}

The study was conducted to identify the status of oral hygiene practices, its associated factors, and evaluate the effectiveness of oral health education package in improving the practices on oral hygiene among 6-8 grade students of Bajrabarahi Municipality. The first objective of the study was to assess the status of oral hygiene practices among the participants. Regarding tooth brushing practices, all 330 students responds that they brush their teeth daily. Only one third of the student brush their teeth twice a day. Around twenty percent of the student followed the appropriate technique of brushing whereas more than fifty percent of the participant used to rinse their mouth after major meal. Regarding the status of oral hygiene practice more than fifty percent of the student have below average practice on oral hygiene. The second objective of the study was to identify the knowledge on oral hygiene among the participants. Maximum number of the students have adequate knowledge regarding frequency of brushing, appropriate technique of brushing, rinsing.

Third objective is to examine the factors associated with oral hygiene practices. Significant association was found between mothers education level and perceived barrier with the oral hygiene practice. Fourth objective was to develop the oral health education package. Based on the findings of the baseline study oral health education package was developed. The oral health education package was then implemented in 2 school which was randomly selected from the 5 school of the baseline study. According to the baseline study it was found that the students have less knowledge and practice on appropriate technique of brushing. So the oral health education package was developed on appropriate technique of brushing. The intervention consisted of one day 2 hour session. The content of the awareness package was focused on increasing the participant's perceived susceptibility and severity of oral health problems, increasing the perception of benefit of proper oral hygiene practices and decreasing their perception of barrier. Message was designed according to the appropriate analysis of the methods, media and audiences. Fifth objective was to evaluate the effectiveness of the oral health education package. The evaluation of the package was done using the quasi experimental study design. The oral health education package was found to be statistical significant in increasing the knowledge, health belief and practice on oral hygiene among the intervention group. It's also concluded that the behavior of appropriate technique of brushing is easy to change through the health education rather than the practice of brushing twice a day.

\section{Recommendation}

Based on the findings it was concluded that the oral hygiene practice was inadequate among the students. So effective oral health awareness program should be conducted in school. Oral health education package is effective in increasing students' knowledge, belief and practice on oral hygiene. Oral health education should be developed and implement at national level. The developed educational package in the study can be integrated in school curriculum.

\section{Acknowledgments}

None.

\section{Conflicts of interest}

The author declares there is no conflict of interest.

\section{References}

1. WHO. Oral health. Fact sheet N³18. 2012.

2. The free dictionary. Oral Hygiene.
3. Sarwar A, Kabir M, Rahman A, et al. Oral hygiene practice among the primary school children in selected rural areas of Bangladesh. Journal of Dhaka National Medical College \& Hospital. 2012;18(1):43-48.

4. Bimal MK. Knowledge and Expressed Practices of Oral Hygiene among School going Children in Govt. Middle School Kishangarh, Ludhiana, Punjab. Journal of Oral Health Research. 2016;7(1).

5. A challenge for oral disease a call for global action, fdi oral health federation. Second edition. 2015.

6. Shamsi M, Hidarnia A, Niknami S. The effect of educational program on increasing oral health behavior among pregnant women: Applying health belief model. Health Education \& Health Promotion. 2014;1(2):21-36.

7. Soltani R, Ali Eslami A, Mahaki B, et al. Do Maternal Oral Health-Related Self-Efficacy and Knowledge Influence Oral Hygiene Behavior of their Children? International Journal of Pediatrics. 2016;4(7):2035-2042.

8. Kasmaei P, Amin Shokravi F, Hajizadeh E, et al. Role of Oral Hygiene Beliefs in Regular Brushing among the 9-10 Years Old Female Students. Health Education \& Health Promotion. 2014;1:45-58.

9. Nayana UJ. Knowledge of children regarding oral hygiene: A school based descriptive study. Journal of scientific and innovative research. 2014;3(2):134-138.

10. Oral health in Nepal. Dentistryiq.com. 2017.

11. Oral Hygiene Basics. Colgate.com. 2017.

12. Dixit P, Dixit S, Singh R, Khanal P. Oral hygiene in awareness and practices among the Nepalese. Journal of Nepal Dental Association. 2013;13(2).

13. Kum A, Singh VP. Knowledge, Attitude and Practice of Oral Hygiene in Children of Eastern Nepal. IOSR Journal of Dental and Medical Sciences (IOSR-JDMS).1(13):93-99.

14. Shakya A, Sherestha M, Srivastava A, et al. Prevalence of primary drug resistant tuberculosis in a tertiary care hospital, Nepal. Journal of Chitwan Medical College. 2014;4(9).

15. Bertness J. Promoting oral health in schools. A resource guide: National Maternal and Child Oral Health Resource Center; 2009. p. 1-35.

16. Petersen PE. The World Oral Health Report 2003: continuous improvement of oral health in the 21 st century-the approach of the WHO Global Oral Health Programme. Community Dentistry and oral epidemiology. 2003;31(S1):3-24.

17. Kasmaei P, Shokravi FA, Hidarnia A, et al. Brushing behavior among young adolescents: does perceived severity matter. BMC public health. 2014;14(1):8

18. Yatish Kumar Sanadhya JPT, Darshan Devang Divakar, Sonia Pareek, et al. Effectiveness of oral health education on knowledge, attitude, practices and oral hygiene status among 12-15-year-old schoolchildren of fishermen of Kutch district, Gujarat, India. Int Marit Heath. 2014;65(3)-99-105.

19. Shenoy RP, Sequeira PS. Effectiveness of a school dental education program in improving oral health knowledge and oral hygiene practices and status of 12-to 13-year-old school children. Indian Journal of Dental Research. 2010;21(2):253-259.

20. Kuppuswamy VL, Murthy S, Sharma S, et al. Oral hygiene status, knowledge, perceptions and practices among school settings in rural South India. Oral Health Dent Manag. 2014;13(1):146-154.

21. Thapa P, Aryal K, Dhimal M, et al. Oral Health Condition of School Children in Nawalparasi District, Nepal. Journal of Nepal Health Research Council. 2015;13(29):7-13.

22. Reddy V, Bennadi D, Gaduputi S, et al. Oral health related knowledge, attitude, and practice among the pre-university students of Mysore city. Journal of International Society of Preventive and Community Dentistry. 2014;4(3):154-158. 
23. Kamran A, Bakhteyar K, Heydari H, et al. Survey of oral hygiene behaviors, knowledge and attitude among school children: a crosssectional study from Iran. Int J Health Sci. 2014;2(2):83-95.

24. Nur-E-Saud AA, Ayrin Parvin, Shahriar Zaman, et al. Study on Oral Hygiene: Awareness and Practices Among the School Going Children in Rajshahi Division. Research \& Reviews Journal of Dental Science. 2016.
25. Petersen PE, Peng B, Tai B, et al. Effect of a school-based oral health education programme in Wuhan City, Peoples Republic of China. International dental journal. 2004;54(1):33-41. 